\title{
SUBDOSES DE GLYPHOSATE NO DESEMPENHO FITOMÉTRICO E BIOQUÍMICO DE SOJA CONVENCIONAL E TRANSGÊNICA
}

\author{
Subdoses of glyphosate in phytometric and biochemical performance of conventional and transgenic soybean
}

André Prechlak Barbosa ${ }^{1 *}$; Gustavo Henrique Freiria²; Guilherme Renato Gomes ${ }^{3}$; Douglas Junior Bertoncelli4; José Henrique Bizzarri Bazzo ${ }^{5}$, Luiz Henrique Campos de Almeida ${ }^{6}$; Luiz Abilio Ribeiro Alves ${ }^{7}$

\author{
${ }^{1}$ Doutorando em Agronomia; Universidade Estadual de Londrina (UEL); E-mail: andreprechlak@gmail.com; *Autor para \\ correspondência \\ 2 Doutorando em Agronomia; Universidade Estadual de Londrina (UEL); E-mail: gustavo-freiria@hotmail.com \\ ${ }^{3}$ Doutorando em Agronomia; Universidade Estadual de Londrina (UEL); E-mail: guilhermerenatogomes@hotmail.com \\ ${ }^{4}$ Doutorando em Agronomia; Universidade Estadual de Londrina (UEL); E-mail: di_bertoncelli@hotmail.com \\ ${ }^{5}$ Doutorando em Agronomia; Universidade Estadual de Londrina (UEL); E-mail: agro.bazzo@gmail.com \\ ${ }^{6}$ Doutorando em Agronomia; Universidade Estadual de Londrina (UEL); E-mail: caluizhenrique@msn.com \\ ${ }^{7}$ Mestrando em Agronomia; Universidade Estadual de Londrina (UEL); E-mail: labilioalves@gmail.com
}

\section{Artigo enviado em 26/01/2017, aceito em 16/01/2018 e publicado em 10/04/2018.}

Resumo - O manejo do herbicida glyphosate pode interferir diretamente no desempenho fitométrico e bioquímico das plantas de soja e pouco se conhece sobre os efeitos que subdoses do glyphosate tem sobre genótipos de soja convencional e transgênica. Nesse contexto, o objetivo nesse estudo foi avaliar o efeito das subdoses de glyphosate sobre o desempenho de plantas de soja transgênica e convencional em condições de casa de vegetação. $\mathrm{O}$ delineamento experimental foi inteiramente casualizado, em esquema fatorial $2 \times 6$, sendo dois genótipos de soja e seis subdoses do herbicida glyphosate $\left(0 ; 3,5 ; 7,0 ; 10,5 ; 14,0\right.$ e $17,5 \mathrm{~g}$ e.a ha $\left.{ }^{-1}\right)$, com cinco repetições. Foram avaliadas características fitométricas e bioquímicas das plantas de soja, e os dados submetidos a análise de variância, aplicandose o teste $\mathrm{F}$ e análise de regressão até segundo grau para subdoses, todos os testes a $5 \%$ de probabilidade de erro. $\mathrm{O}$ desempenho fitométrico das plantas de soja possui influência inerente ao genótipo, sendo a massa seca de trifólios e o diâmetro de haste principal afetados negativamente pelas subdoses de glyphosate. A aplicação de subdoses de glyphosate modifica os teores de pigmentos fotossintéticos dos genótipos de soja, havendo resposta diferenciada entre eles. As maiores subdoses incrementaram o teor de pigmentos das folhas de soja.

Palavras-Chave - Glycine max (L.) Merrill. Genótipos. Hormese.

\begin{abstract}
The management of the herbicide, glyphosate can directly interfere in the phytometric and biochemical performance of soybean plants and little is known about the effects that glyphosate subdoses have in conventional and transgenic soybean genotypes. In this context, the aim of this study was to evaluate the effect of subdoses of glyphosate on the performance of transgenic and conventional soybean plants under greenhouse conditions. The experimental design was completely randomized, in a $2 \times 6$ factorial scheme, with two soybean genotypes and six subdoses of glyphosate herbicide $\left(0 ; 3.5 ; 7.0 ; 10.5 ; 14.0\right.$ and $17.5 \mathrm{~g}$ and ha- $\left.{ }^{-1}\right)$ with five replicates. Phytometric and biochemical characteristics of soybean plants was evaluated and the analysis of variance was carried out by the $\mathrm{F}$ test, comparing the means performed by the Tukey test for genotypes, and by regression analysis up to second degree for subdoses, all tests at $5 \%$ of error probability. The phytometric performance of soybean plants has influence inherent to the genotype, with the dry mass of leafs and the main stem diameter negatively affected by the glyphosate subdoses. The application of glyphosate subdoses modifies the contents of photosynthetic pigments of the soybean genotypes, with a differentiated response between them. The highest subdoses increased the pigment content of soybean leaves.
\end{abstract}

Keywords - Glycine $\max$ (L.) Merrill. Genotypes. Hormesis. 


\section{INTRODUÇÃO}

A soja (Glycine max (L.) Merrill) é uma cultura que apresenta em sua constituição grande percentagem de óleo e proteína, o que a classifica como matéria-prima bastante relevante nacional e internacionalmente. No Brasil, é a cultura de grãos mais produzida, posicionando o país entre os maiores produtores mundiais (SANTOS et al., 2012), sua produtividade atual é em média de $3.072 \mathrm{~kg} \mathrm{ha}^{-1}$, com a produção nacional estimada para safra 2016/17 em 103,778 milhões de toneladas em uma área superior a 33,787 milhões de hectares (CONAB, 2016).

$\mathrm{O}$ potencial genético para rendimento de grãos da cultura da soja é elevado, no entanto devido a diversos fatores como cultivares, condições ambientais e tratos culturais, que interferem no crescimento e desenvolvimento e na intensidade fotossintética das plantas, ainda existe uma lacuna grande entre o potencial produtivo e as médias atuais das áreas comerciais da leguminosa (LEITE et al., 2015). A fotossíntese depende da interceptação da luz e da conversão em energia química, esta é afetada por fatores abióticos e bióticos, e pelo manejo da cultura, que podem alterar a área e arquitetura foliar das plantas, assim como a composição bioquímica das mesmas (LOPES; LIMA, 2015).

Dentre os manejos mais usuais na cultura da soja está a aplicação de herbicidas pós-emergentes e dentre eles o glyphosate é o mais utilizado, principalmente após o advento da transgenia que proporciona tolerância das plantas a esse herbicida (ALBRECHT; MISSIO, 2013). O glyphosate é uma das mais importantes ferramentas no controle de diversas espécies de plantas daninhas. Sua ação afeta a síntese de metabólitos secundários devido ao bloqueio da rota do ácido chiquímico, com muitas implicações fisiológicas (SAUNDERS; PEZESHKI, 2015).

Alguns trabalhos com aplicação de subdoses do herbicida glyphosate, encontraram estímulo ao crescimento, como: aumento na área foliar, na altura das plantas e na produção vegetal (VELINI et al., 2008; SALGADO, PEREIRA, KUVA, ALVES, 2017), fato relacionado ao efeito de "hormese", atribuído ao estimulo proporcionado por substâncias toxicas quando utilizadas em subdoses (CEDERGREEN; HANSEN; ARENTOFT, 2016). Contudo, segundo Melhorança Filho et al. (2011) a continua compreensão do comportamento de plantas transgênicas e convencionais submetidas ao uso de glyphosate em diversas condições é de fundamental importância para a adoção do manejo dessa tecnologia.
Portanto, o objetivo nesse estudo foi avaliar o efeito das subdoses de glyphosate sobre o desempenho de plantas de soja transgênica e convencional em condições de casa de vegetação.

\section{MATERIAL E MÉTODOS}

O experimento foi realizado em casa de vegetação situada no município de Londrina, Estado do Paraná. A localização foi sob coordenadas de latitude $23^{\circ} 20^{\prime} 32^{\prime \prime}$ sul e longitude $51^{\circ} 12$ ' $32^{\prime \prime}$ oeste e altitude média de 540 metros. Foram utilizados dois genótipos de soja: cultivar BMX 6160 RSF IPRO e linhagem UEL 175. O primeiro transgênico e tolerante a glyphosate e o segundo convencional e sensível ao herbicida. A semeadura foi realizada em vasos contendo oito litros de solo, sendo este classificado como LATOSSOLO Vermelho distroférrico, foram depositadas cinco sementes por vaso e foi realizado o desbaste no estádio V2 da soja, em que foram mantidas apenas duas plantas.

As características químicas do solo, determinadas antes da instalação do experimento, foram representadas por: $\mathrm{pH}\left(\mathrm{CaCl}_{2}\right)=5,50 ; \mathrm{P}=8,55$ $\mathrm{mg} \mathrm{dm}{ }^{-3} ; \mathrm{K}^{+}=0,60 \mathrm{cmolc} \mathrm{dm}^{-3} ; \mathrm{Ca}^{2+}=5,30 \mathrm{cmol}_{\mathrm{c}}$ $\mathrm{dm}^{-3} ; \mathrm{Mg}^{2+}=2,20 \mathrm{cmolc} \mathrm{dm}^{-3} ; \mathrm{Al}^{3+}=0 \mathrm{cmol}_{\mathrm{c}} \mathrm{dm}^{-3}$; $\mathrm{H}^{+}+\mathrm{Al}^{3+}=4,28 \mathrm{cmol}_{\mathrm{c}} \mathrm{dm}^{-3} ; \mathrm{CTC}=13,38 \mathrm{cmol}_{\mathrm{c}}$ $\mathrm{dm}^{-3}$ e $\mathrm{V}=68,01 \%$. A adubação de base consistiu da aplicação de $25 \mathrm{~g}$ por vaso do formulado 08-28-16 (equivalente a $312,5 \mathrm{~kg} \mathrm{ha}^{-1}$ ), que disponibilizou $5 \mathrm{~kg}$ de nitrogênio, $87,5 \mathrm{~kg}$ de fósforo e $50 \mathrm{~kg}$ de potássio por hectare. Durante o período experimental, foram realizadas irrigações diárias e os manejos agrotecnológicos foram realizados de acordo com as recomendações para a cultura (EMBRAPA, 2013).

$\mathrm{O}$ herbicida glyphosate utilizado foi $\mathrm{O}$ produto comercial Trop ${ }^{\circledR}$, de formulação correspondente a $480 \mathrm{~g} \mathrm{~L}^{-1}$ de sal de isopropilamina de $\mathrm{N}$-(fosfonometil) glicina, $360 \mathrm{~g} \mathrm{~L}^{-1}$ do equivalente ácido (e.a) de $\mathrm{N}$-(fosfonometil) glicina (glyphosate) e $684 \mathrm{~g} \mathrm{~L} \mathrm{~L}^{-1}$ de ingredientes inertes. A dose mínima recomendada para ação herbicida desse produto é de $360 \mathrm{~g}$ e.a por hectare.

O delineamento experimental foi $O$ inteiramente casualizado, em esquema fatorial $2 \times 6$, sendo dois genótipos de soja e seis subdoses do herbicida glyphosate $(0 ; 3,5 ; 7,0 ; 10,5 ; 14,0$ e 17,5 g e.a $\mathrm{ha}^{-1}$ ), com cinco repetições. A aplicação das subdoses foi realizada no estádio de desenvolvimento V3 (segundo nó do caule visível e primeira folha trifoliolada completamente desenvolvida), com as plantas totalmente túrgidas e sem sinais de estresse.

Os tratamentos com o herbicida, nas respectivas subdoses, foram preparados utilizando-se volume de calda equivalente a $200 \mathrm{~L} \mathrm{ha}^{-1}$, e a 
aplicação foi realizada com auxílio de um pulverizador costal propelido a $\mathrm{CO}_{2}$, em pressão a irrigação com o intuito de proporcionar máxima absorção do produto pelas plantas. Posteriormente, os vasos foram acomodados aleatoriamente no interior da casa de vegetação, aos quais tiveram a irrigação reestabelecida no fim da manhã do dia seguinte.

Quanto ao desempenho fitométrico das plantas, foram avaliadas aos 30 dias após a aplicação os seguintes parâmetros: altura de planta: mensurada da base do caule até a inserção do último trifólio, com auxílio de régua graduada em centímetros; diâmetro do caule: determinado no segundo entrenó visível, com auxílio de um paquímetro graduado em milímetros; área foliar: realizada com auxílio do equipamento portátil CI - 203, expressa em centímetros quadrados; massa seca de trifólios e de parte aérea: os trifólios, caule e ramos das plantas foram separados, e realizou-se a secagem do material em estufa de circulação forçada de ar sob temperatura de $65^{\circ} \mathrm{C}$ por 72 horas, até massa constante. Posteriormente, procedeu-se a pesagem em balança com precisão de três casas decimais, e os resultados expressos em gramas.

$\mathrm{Na}$ determinação do conteúdo de pigmentos, foram coletadas amostras de $0,2 \mathrm{~g}$ de tecido foliar fresco, armazenadas em frascos com 10 $\mathrm{ml}$ de acetona a $80 \%$. Posteriormente, os extratos foram filtrados $e$ as leituras realizadas por espectrofotometria nos comprimentos de onda de 663, 645 e 434 para clorofilas a (Cla), b (Clb) e carotenoides (Cart), respectivamente. As determinações dos teores de clorofila e carotenoides basearam-se nas equações relacionadas a seguir, segundo Whitham et al. (1971) e os resultados foram expressos em miligramas por grama de massa fresca $\left(\mathrm{mg} \mathrm{gmf}^{-1}\right)$.

$$
\begin{gathered}
\mathrm{Cla}=(11,24 \times \mathrm{A} 663-2,04 \times \mathrm{A} 645) \\
\mathrm{Clb}=(20,13 \times \mathrm{A} 645-4,19 \times \mathrm{A} 663) \\
\mathrm{Cart}=((1000 \times \mathrm{A} 434-1,90 \times \mathrm{Cla}-63,14 \times \\
\mathrm{Clb})) / 214
\end{gathered}
$$

As análises de variâncias foram conduzidas aplicando-se o teste $\mathrm{F}$ ao nível de $5 \%$ de probabilidade para genótipos, e por análise de regressão até terceiro grau para subdoses.

\section{RESULTADOS E DISCUSSÃO}

Conforme a análise de variância, para a característica área foliar não houve efeito significativo para nenhuma das fontes de variação analisadas. Ferreira et al. (2013) constatou ausência de alteração do desenvolvimento foliar da soja em doses de até constante de 30 psi. Após as aplicações, suspendeu-se

2.880 g .e.a. ha-1 de glyphosate aplicadas em V2, isso demonstra a ampla capacidade de compensação da cultura no crescimento de área fotossintetizante.

Já para as demais características fitométricas (altura de planta e massa seca de trifólios e de parte aérea), houve efeito isolado para genótipo e para subdoses de glyphosate, para as variáveis bioquímicas (teores de clorofila a, b e carotenoides), houve interação genótipo e subdoses de glyphosate.

O genótipo BMX 6160, apresentou as maiores alturas se comparada ao UEL 175 (Tabela 1), fato que parece ser melhor explicado pelo fator genético e não pela diferença de resposta do herbicida para material transgênico ou convencional, visto que o primeiro material possui hábito de crescimento indeterminado e o segundo determinado. Segundo Pires et al. (2012) essa diferença de porte das plantas de soja é bastante influenciada pelo genótipo, e os autores confirmaram isso ao testar oito genótipos de soja em dois locais de cultivo.

Apesar de apresentar diferença significativas para Subdoses de glyphosate, o ajuste do modelo de regressão para a variável altura não foi adequado $\left(\mathrm{R}^{2}\right.$ $=11,13 \%$ ), portanto o gráfico de regressão não foi apresentado.

Para diâmetro do colmo só houve diferenciação dos genótipos nas subdoses de 0 e 10,5 g e.a ha ${ }^{-1}$, na primeira subdose maiores valores para $\mathrm{O}$ genótipo UEL 175 e na segunda, uma inversão, com maiores valores atribuídos para BMX 6160 (Tabela 1).

Tal diferenciação entre genótipos também foi relatada por Solano e Yamashita (2011), ao trabalhar com duas cultivares RR.

Ao contrário do observado para área foliar, foi possível uma diferenciação dos genótipos para a característica massa seca de parte aérea, com maiores valores para BMX 6160, com exceção nas subdoses 0 ; 7,0 e 17, 5 g e.a ha ${ }^{-1}$.

A aplicação de subdoses de glyphosate em algumas espécies de plantas como soja, eucalipto, arroz, trigo e em diferentes condições, apontam diversas reações, destacando-se aumento na área foliar, altura das plantas e produção vegetal (VELINI et al., 2008). Alguns trabalhos mostram problemas do uso do glyphosate relacionados a redução no desenvolvimento vegetativo e produtividade em cultivos comerciais (SALGADO, PEREIRA, KUVA, ALVES, 2017).

$\mathrm{Na}$ dose 0 (ausência do glyphosate), o genótipo UEL175 apresentou as maiores médias para o teor de pigmentos fotossintetizantes, em relação a BMX 6160, indicando diferença intrínseca entre eles. Para o teor de clorofila a, o genótipo BMX 6160 
apresentou os maiores teores nas concentrações de 3,5, 10,5 e $14 \mathrm{~g}$ e.a ha ${ }^{-1}$ e o genótipo UEL 175 as maiores médias nas concentrações 0,7 e $17,5 \mathrm{~g}$ e.a ha

Para teor de carotenoides, o genótipo BMX 6160 apresentou as menores médias em relação ao UEL 175 em todas as subdoses testadas, com exceção da subdose $14 \mathrm{~g}$ e.a ha-1 ${ }^{-1}$ em que não houve diferença significativa entre os dois genótipos.

Segundo Reddy et al. (2008), o glyphosate pode reduzir indiretamente a síntese de clorofila, por meio da inibição da porfirina, precursora do ácido aminolevulínico.

Tabela 1. Características fitométricas e químicas das cultivares UEL 175 e BMX 6160 RSF IPRO em função de diferentes subdoses de glyphosate.

\begin{tabular}{|c|c|c|c|c|}
\hline \multirow{3}{*}{$\begin{array}{c}\text { Subdoses de glyphosate }(\mathrm{g} \\
\left.\text { e.a. } \mathrm{ha}^{-1}\right)\end{array}$} & \multicolumn{4}{|c|}{ Cultivar } \\
\hline & UEL 175 & BMX 6160 & UEL 175 & BMX 6160 \\
\hline & \multicolumn{2}{|c|}{$\mathrm{AP}^{1}(\mathrm{~cm})$} & \multicolumn{2}{|c|}{$\mathrm{DHP}(\mathrm{cm})$} \\
\hline 0 & 56,94 & 81,39 & $0,46 \mathrm{~A}$ & $0,42 \mathrm{~B}$ \\
\hline 3,5 & 63,38 & 84,72 & $0,28 \mathrm{~A}$ & $0,28 \mathrm{~A}$ \\
\hline 7,0 & 60,20 & 93,27 & $0,25 \mathrm{~A}$ & $0,27 \mathrm{~A}$ \\
\hline 10,5 & 56,48 & 92,05 & $0,23 \mathrm{~B}$ & $0,27 \mathrm{~A}$ \\
\hline 14,0 & 60,20 & 93,27 & $0,25 \mathrm{~A}$ & $0,27 \mathrm{~A}$ \\
\hline 17,5 & 56,48 & 92,05 & $0,27 \mathrm{~A}$ & $0,27 \mathrm{~A}$ \\
\hline \multirow[t]{2}{*}{ Média } & $59,63 \mathrm{~B}$ & $89,53 \mathrm{~A}$ & 0,29 & 0,30 \\
\hline & \multicolumn{2}{|c|}{$\mathrm{AF}\left(\mathrm{cm}^{2}\right)$} & \multicolumn{2}{|c|}{$\operatorname{MST}(\mathrm{g})$} \\
\hline 0 & 3,80 & 4,03 & $7,06 \mathrm{~A}$ & $7,09 \mathrm{~A}$ \\
\hline 3,5 & 3,45 & 4,15 & $6,35 \mathrm{~B}$ & $7,23 \mathrm{~A}$ \\
\hline 7,0 & 3,28 & 3,19 & $6,27 \mathrm{~A}$ & $5,89 \mathrm{~A}$ \\
\hline 10,5 & 3,50 & 3,88 & $6,04 \mathrm{~B}$ & $6,99 \mathrm{~A}$ \\
\hline 14,0 & 2,89 & 3,20 & $5,44 \mathrm{~B}$ & $6,34 \mathrm{~A}$ \\
\hline 17,5 & 3,12 & 2,85 & $5,81 \mathrm{~A}$ & $5,20 \mathrm{~A}$ \\
\hline \multirow[t]{2}{*}{ Média } & $3,34 \mathrm{~B}$ & $3,55 \mathrm{~A}$ & 6,16 & 6,46 \\
\hline & \multicolumn{2}{|c|}{ MSPA (g) } & \multicolumn{2}{|c|}{$\mathrm{Cla}\left(\mathrm{mg} \mathrm{gmf}^{-1}\right)$} \\
\hline 0 & $7,06 \mathrm{~A}$ & $7,09 \mathrm{~A}$ & $335,30 \mathrm{~A}$ & $195,86 \mathrm{~B}$ \\
\hline 3,5 & $6,35 B$ & $7,23 \mathrm{~A}$ & $208,20 \mathrm{~B}$ & $282,94 \mathrm{~A}$ \\
\hline 7,0 & $6,27 \mathrm{~A}$ & $5,89 \mathrm{~A}$ & $286,29 \mathrm{~A}$ & $246,19 B$ \\
\hline 10,5 & $6,04 \mathrm{~B}$ & $6,99 \mathrm{~A}$ & $247,49 B$ & $317,26 \mathrm{~A}$ \\
\hline 14,0 & $5,44 \mathrm{~B}$ & $6,34 \mathrm{~A}$ & $286,81 B$ & $364,72 \mathrm{~A}$ \\
\hline 17,5 & $5,81 \mathrm{~A}$ & $5,20 \mathrm{~A}$ & $490,18 \mathrm{~A}$ & $472,92 \mathrm{~B}$ \\
\hline \multirow[t]{2}{*}{ Média } & 6,16 & 6,46 & 309,03 & 313,32 \\
\hline & \multicolumn{2}{|c|}{$\mathrm{Clb}\left(\mathrm{mg} \mathrm{gmf}^{-1}\right)$} & \multicolumn{2}{|c|}{ Cart $\left(\mathrm{mg} \mathrm{gmf}^{-1}\right)$} \\
\hline 0 & $73,85 \mathrm{~A}$ & $13,86 \mathrm{~B}$ & $281,02 \mathrm{~A}$ & $212,53 \mathrm{~B}$ \\
\hline 3,5 & $115,4 \mathrm{~A}$ & $37,38 \mathrm{~B}$ & $310,13 \mathrm{~A}$ & $235,69 B$ \\
\hline 7,0 & $213,00 \mathrm{~A}$ & $91,62 \mathrm{~B}$ & $297,61 \mathrm{~A}$ & $257,67 \mathrm{~B}$ \\
\hline 10,5 & $64,26 \mathrm{~B}$ & $108,22 \mathrm{~A}$ & $374,72 \mathrm{~A}$ & $349,48 \mathrm{~B}$ \\
\hline 14,0 & $92,52 \mathrm{~B}$ & $244,21 \mathrm{~A}$ & $367,38 \mathrm{~A}$ & $377,28 \mathrm{~A}$ \\
\hline 17,5 & $82,34 \mathrm{~B}$ & $452,91 \mathrm{~A}$ & $586,27 \mathrm{~A}$ & $551,32 \mathrm{~B}$ \\
\hline Média & 1061,91 & 158,04 & 369,52 & 330,66 \\
\hline
\end{tabular}

*Médias seguidas pela letra na linha não diferem entre si pelo teste $\mathrm{F}$ a $5 \%$ de significância. ${ }^{1} \mathrm{CV}(\%)=8,42$ (AP - Altura de planta); 9,11 (DHP Diâmetro da haste principal); 13,00 (AF - Área foliar); 10,86 (MST - Massa seca dos trifólios); 9,11 (MSPA - Massa seca de parte aérea); 0,56 (Cla Clorofila a); 2,80 (Clb - Clorofila b); 2,15 (Cart - Carotenoide). 
Por outro lado, Ketel (1996) observou incrementos no conteúdo de clorofila das plantas de Chenopodium album tratadas com subdose de glyphosate, verificando o aumento de 1,8 e 2 vezes mais clorofila por unidade de massa fresca de folha quando tratado com 1,25 e $0,62 \mathrm{~mL} \mathrm{ha}^{-1}$ de glyphosate, respectivamente.

Para ambos genótipos foi constatado um ajuste quadrático (Figura 1A) para o diâmetro da haste principal, com pontos de mínima calculado de 10,526 (UEL 175) e 11,500 (BMX 6160).

Ressalta-se, que em todas as subdoses houve decréscimo de diâmetro da haste principal em relação ao controle, o que evidencia, o efeito fitotóxico do glyphosate sobre o crescimento da planta.

Foi verificado ainda resposta linear decrescente da massa seca de trifólios (Figura 1B), para os dois genótipos que indica que nas subdoses estudadas não foi possível visualizar o efeito de hormese.

Velini et al. (2008), em estudo de subdoses de glyphosate, relataram diferentes respostas para genótipos transgênicas e convencionais de soja, com maiores respostas de hormese para esta última em subdoses de $18 \mathrm{~g}$ e. ha $^{-1}$.

Contudo, segundo Melhorança Filho et al. (2011), situações ambientais distintas, apresentam grande participação na determinação dos resultados por apresentar em alguns casos maior força no desenvolvimento da soja quando comparadas à aplicação de subdose de glyphosate.

O aumento dos teores de clorofilas a (Figura 2A) em resposta ao aumento das subdoses de glyphosate em ambos genótipos de soja está relacionado a maior síntese destes pigmentos em reposta ao estresse promovido pela aplicação do herbicida, conforme observado por Meschede et al. (2011) para a cultura da cana-de-açúcar.

Para o teor de clorofila b (Figura 2B), foi ajustado o modelo quadrático para a cultivar BMX 6160, com ponto de mínimo de 2,42, e não foi possível realizar um ajuste matemático biologicamente explicável para o genótipo UEL 175, inferindo em uma tolerância diferenciada das cultivares as subdoses de glyphosate.

A
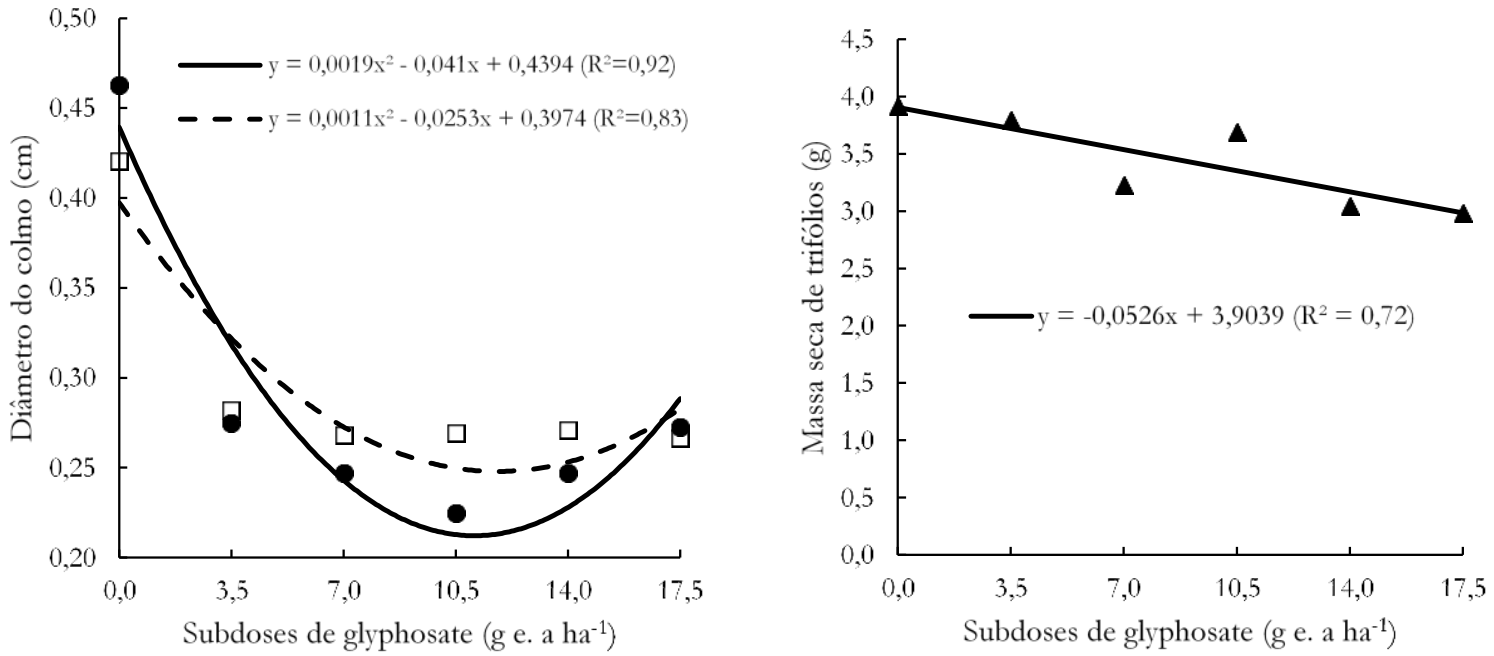

Figura 1. Diâmetro da haste principal (A) e massa seca de trifólios (B) de dos genótipos de soja UEL 175 (•), BMX 6160 RSF IPRO (口) e média dos genótipos ( $\Delta$ ) em função de subdoses de glyphosate.

Pelos resultados da Figura 2C, observa-se que os genótipos UEL 175 e BMX 6160 apresentaram tendência de decréscimo nos teores de carotenoides até os pontos de mínimo de 3,62 e 0,79, respectivamente, com aumento da síntese a partir destes pontos.

Os resultados obtidos para os teores de pigmentos fotossintéticos são coerentes com o encontrado por Meschede et al. (2011) que ao trabalhar com a cultura da cana-de-açúcar obteve resposta semelhante com o incremento das doses de glyphosate.

O aumento dos pigmentos fotossintéticos após o ponto de mínima resposta parece estar associado a diminuição da massa seca foliar e da manutenção da área foliar, que resultou em menor massa especifica de folha, e consequentemente, maior concentração desses compostos no tecido.

A aplicação de subdoses de glyphosate modifica os teores de pigmentos fotossintéticos dos 
genótipos de soja, havendo resposta diferenciada entre eles. As maiores subdoses incrementa o teor de pigmentos das folhas de soja.

A
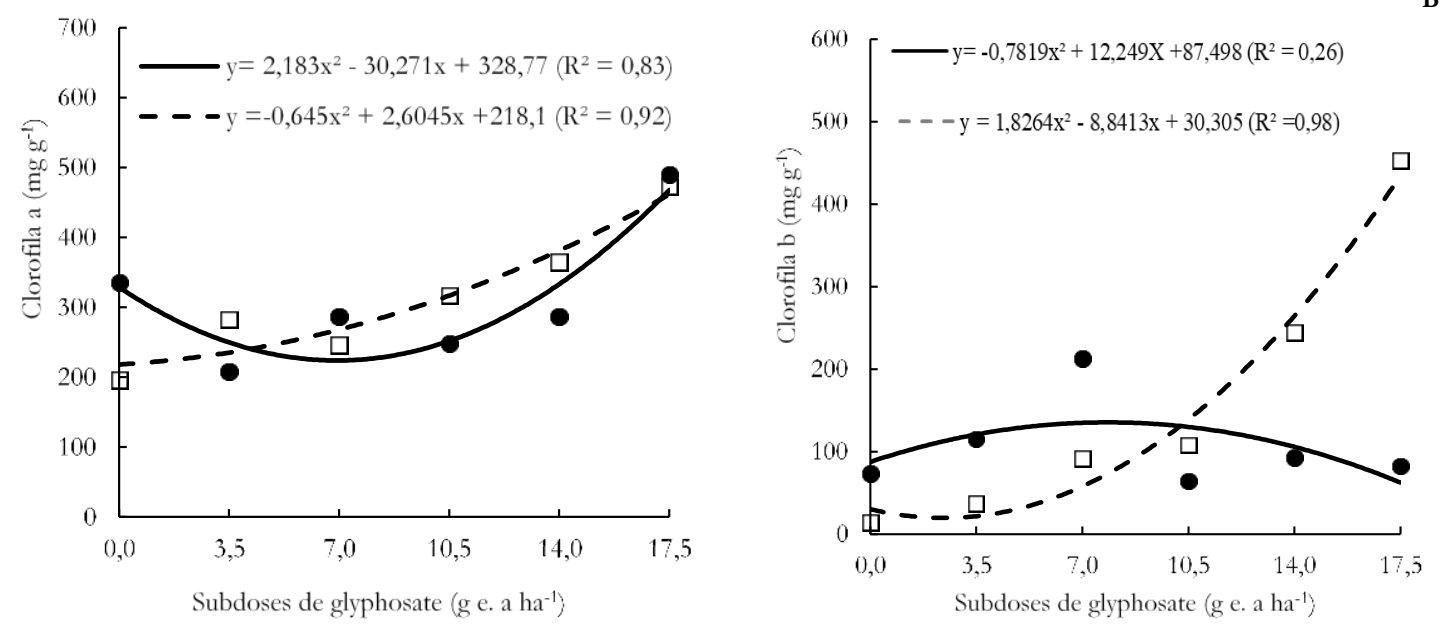

C

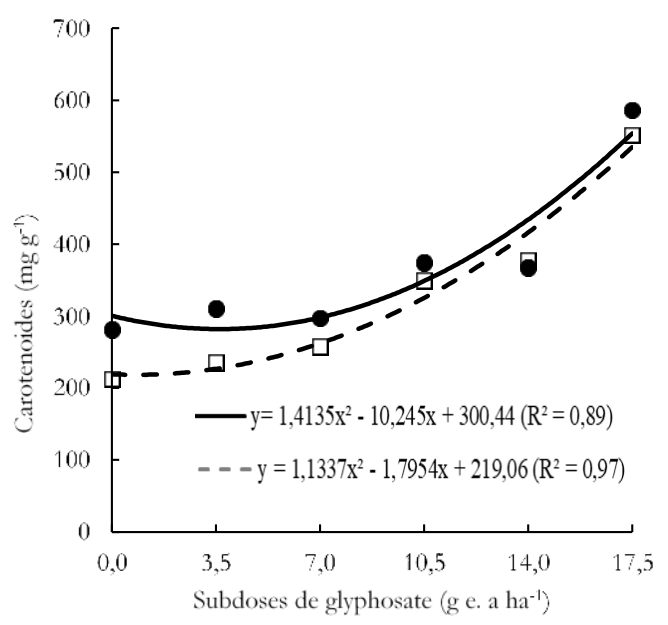

Figura 2. Teor de clorofila a (A), teor de clorofila b (B) e teor de carotenoides (C) de dois genótipos de soja UEL 175 $(\bullet)$, BMX 6160 RSF IPRO ( $\square$ ) em função de subdoses de glyphosate.

\section{CONCLUSÕES}

O desempenho fitométrico das plantas de soja possui grande influência inerente ao genótipo, sendo a massa seca de trifólios e o diâmetro de haste principal afetados negativamente pelas subdoses de glyphosate.

A aplicação de subdoses de glyphosate modifica os teores de pigmentos fotossintéticos dos genótipos de soja, havendo resposta diferenciada entre eles. As maiores subdoses incrementam o teor de pigmentos das folhas de soja. 


\section{REFERÊNCIAS}

ALBRECHT, L. P.; MISSIO, R. F. Manejo de Cultivos Transgênicos. Curitiba, PR: UFPR, 2013.

CEDERGREEN, N.; HANSEN, N. K. K.; ARENTOFT, B. W. The influence of nitrogen and phosphorous status on glyphosate hormesis in Lemna minor and Hordeum vulgare. European Journal of Agronomy, v. 73, p. 107-117, jun. 2016.

CONAB. Companhia Nacional de Abastecimento. Acompanhamento de safra brasileira de grãos, safra 2016/17. Brasília, DF: Ministério da Agricultura, 2017.

EMBRAPA. Empresa Brasileira de Pesquisa Agropecuária. Tecnologias de produção de soja - Região Central do Brasil 2014. Londrina-PR: Embrapa Soja, 2013.

FERREIRA, R. L.; SILVA, A. G.; SIMON, G. A.; TEIXEIRA, I. R.; MARTINS, P. D. S. Glyphosate em pós-emergência na soja Roundup Ready ${ }^{\circledR}$. Revista Brasileira de Herbicidas, v. 12, n. 2, p. 151-161, mai./ago. 2013.

KETEL, D. H. Effect of low doses of metamitron and glyphosate on growth and chlorophyll content of Common Lambsquarters (Chenopodium album). Weed Science, v. 44, n. 1, p. 1-6, jan./mar. 1996.

LEITE, W. D. S.; PAVAN, B. E.; MATOS FILHO, C. H. A.; FEITOSA, F. S.; OLIVEIRA, C. B. Estimativas de parâmetros genéticos e correlações entre caracteres agronômicos em genótipos de soja. Nativa, v. 3, n. 4, p. 241-245, out./dez. 2015.

LOPES, N. F. \& LIMA, M. G. S. Fisiologia da Produção. Viçosa, MG: Editora UFV, 2015.

MELHORANÇA FILHO, A. L.; PEREIRA, M. R. R.; MARTINS, D. Efeito de subdoses de glyphosate sobre a germinação de sementes das cultivares de soja RR e convencional. Bioscience Journal, v. 27, n. 5, p. 689-691, set./out. 2011.

MESCHEDE, D. K.; VELINI, E. D.; CARBONARI, C. A.; SILVA, J. R. M. Alteração fisiológica da cana-de-açúcar pela aplicação de glyphosate e sulfumeturon-methyl. Planta Daninha, v. 29, n. 2, p. 413-419, abr./jun. 2011.
PIRES, L. P. M.; PELUZIO; J. M.; CANCELLIER, L. L.; RIBEIRO, G. R. R.; COLOMBO, G. A; AFFERRI, F. S. Desempenho de genótipos de soja, cultivados na região centro-sul do estado do tocantins, safra 2009/2010. Bioscience Journal, v. 28, n. 2, p. 214-223, mar./abr. 2012.

REDDY, K. N.; RIMANDO, A. M.; DUKE, S. O.; NANDULA, V. K. Aminomethylphosphonic acid accumulation in plant species treated with glyphosate. Journal of agricultural and food chemistry, v. 56, n. 6, p. 2125-2130, fev. 2008.

SALGADO, T. P.; PEREIRA, F. C. M.; KUVA, M. A.; ALVES, P. L. C. A. Effects of glyphosate on growth, yield and wood quality of Eucalyptus urograndis. Journal of tropical forest science, v. 29, n. 3, p. 257-266, jul. 2017.

SANTOS, E. L.; CATTELAN, A. J.; PRETE, C. E. C.; NEUMAIER, N.; OLIVEIRA, M. C. N.; FARIA, J. R. B.; CARVALHO, J. F. C.; NEPOMUCENO, A. L. Water stress affecting nodulation, oil, protein and grain yield of soybean cultivars. Global Science and Technology, v. 05, n. 02, p. 109-120, mai./ago. 2012.

SAUNDERS, L.; PEZESHKI, R. Glyphosate in Runoff Waters and in the Root-Zone: A Review. Toxics, v. 3, n. 4, p. 462-480, nov. 2015.

SOLANO, L.; YAMASHITA, O. M. Cultivo da soja em diferentes espaçamentos entre linhas. Revista Varia Scientia Agrária, v. 2, n. 2, p. 35-47, jul. 2011.

VELINI, E. D.; ALVES, E.; GODOY, M. C.; MESCHEDE, D. K.; SOUZA, R. T.; DUKE, S. O. Glyphosate applied at low doses can stimulate plant growth. Pest Management Science, v. 64, p. 489-496, abr. 2008.

WHITHAM, F. H.; BLAYDES, D. F; DEVLIN, R. M. Experiments in plant physiology. New York, New York: D. Van Nostrand Company, 1971. 